\section{$\underset{\substack{\text { hommes } \\ \text { \& migrations }}}{ }$}

\section{Hommes \& migrations}

Revue française de référence sur les dynamiques

migratoires

1302 | 2013

Le Japon, pays d'immigration?

\title{
Stagiaires et apprentis étrangers au Japon
}

\section{Yoshihiko Kuroda}

\section{(2) OpenEdition \\ Journals}

\section{Édition électronique}

URL : http://journals.openedition.org/hommesmigrations/2464

DOI : 10.4000/hommesmigrations.2464

ISSN : 2262-3353

\section{Éditeur}

Musée national de l'histoire de l'immigration

\section{Édition imprimée}

Date de publication : 1 avril 2013

Pagination : 40-41

ISBN : 978-2-919040-22-3

ISSN : $1142-852 X$

\section{Référence électronique}

Yoshihiko Kuroda, «Stagiaires et apprentis étrangers au Japon», Hommes \& migrations [En ligne], 1302 | 2013, mis en ligne le 31 décembre 2015, consulté le 01 mai 2019. URL : http:// journals.openedition.org/hommesmigrations/2464; DOI : 10.4000/hommesmigrations.2464 


\section{STAGIAIRES ET APPRENTIS ÉTRANGERS AU JAPON}

par YOSHIHIKO KURODA, professeur, sociologue, université de Nagoya

\section{Une main-d'œuvre indispensable et peu visible}

Sur la base du Technical Internship Program (TIP) Entre 2002 et 2007, l'augmentation du nombre de établi en 1993, le Japon a accueilli des stagiaires stagiaires-apprentisaétéremarquable, dépassantles étrangers. Malgré le terme de "stagiaire", il s'agissait concrètement de travailleurs étrangers occupant des emplois classiques. $\mathrm{Au}$ bout d'un an de séjour, le stagiaire, après un examen des qualifications acquises, pouvait obtenir un statut d'"apprenti technicien" (une des catégories possibles du permis de résidence appelé "activités spécifiques"). Le temps de résidence sous ce statut était limité à deux ans maximum. $\mathrm{Au}$ total, le stagiaire-apprenti pouvait rester trois ans au Japon. Depuis le $1^{\text {er }}$ juillet 2010, le statut de "stagiaire" a été supprimé et le temps de résidence autorisé avec un statut d'apprenti technicien a été allongé à trois ans. Étant donné que nous présentons aussi la situation d'avant 2010, nous utiliserons le terme générique de "stagiaire-apprenti".

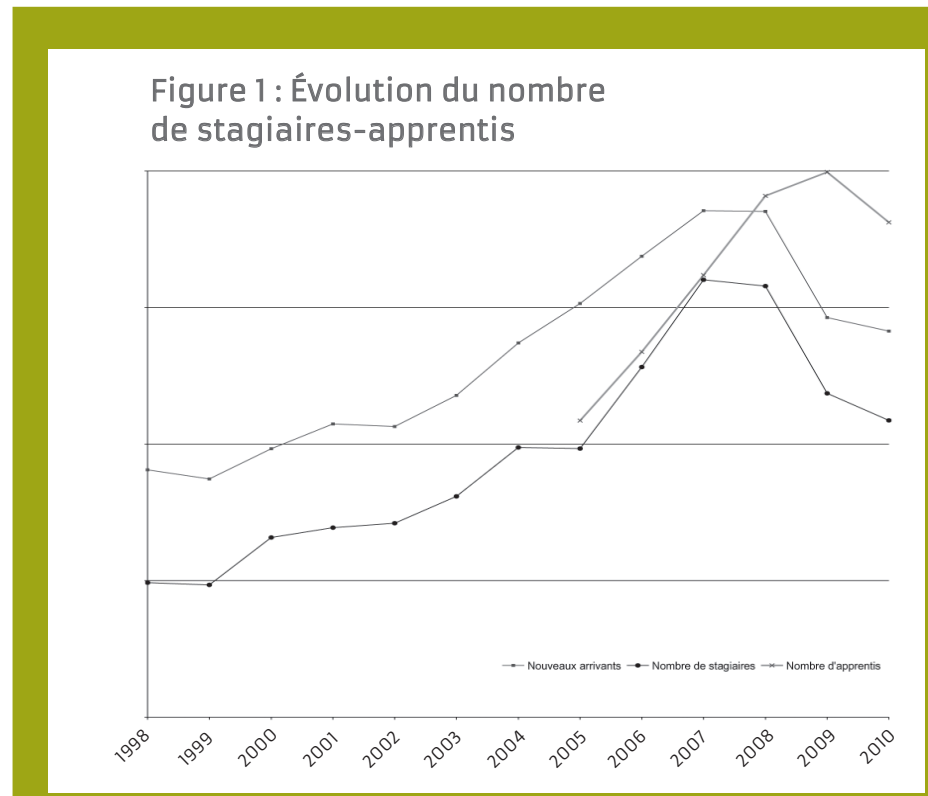

Source : Livre blanc sur l'immigration du Bureau de l'immigration, ministère de la Justice, différentes années. 
$10 \%$ par an. En 2007, le nombre de nouvelles entrées sur l'année a connu un maximum de 102018 personnes. En 2008, sous l'impact de la crise financière de 2008 et du ralentissement économique mondial, le nombre de nouveaux entrants a diminué. Cette baisse a été particulièrement forte en 2008 et 2009. Le nombre de nouveaux stagiaires-apprentis a continué de diminuer en 2010 mais de façon moins forte.

Parmi les stagiaires-apprentis, les Chinois sont les plus nombreux. En 2010, ils comptaient pour $77 \%$ des nouvelles entrées et pour $78 \%$ des résidents enregistrés à une date donnée. Les principaux secteurs d'emploi des stagiaires-apprentis sont la confection femme et enfant, la soudure, la plasturgie, le façonnage, etc. Contrairement aux travailleurs manuels japonais, les stagiairesapprentis étrangers n'ont pas tendance à se concentrer dans des régions particulières. Ils sont certes nombreux dans les régions industrielles de Gifu et Aichi, mais se trouvent dispersés sur l'ensemble du territoire. En outre, plus de la moitié des employeurs sont des petites et Quartier d'affaires de Shinagawa à l'heure de la pause déjeuner. (c) Camille Millerand moyennes entreprises.

La population locale est peu consciente de la présence de ces stagiaires-apprentis. Cela peut s'expliquer par le fait qu'ils ne restent pas longtemps, créent peu de liens et sont, de plus, éparpillés sur le territoire.

Par contre, ils sont remarquablement présents dans les médias, dont les annonces relatives au système des stagiaires et apprentis sont innombrables et portent aussi bien sur les "comportements frauduleux" des entreprises imposant des heures supplémentaires illégales ou contrevenant au droit du travail, que sur les cas de fuite ou de séjour illégal des stagiaires-apprentis; ou encore sur les disputes entre stagiaires-apprentis et employeurs débouchant, parfois, sur des affaires criminelles. En même temps, dans les régions fortement touchées par le manque de main-d'œuvre, ils sont en

quelque sorte considérés comme un atout, un soutien inespéré face aux difficultés économiques.

En 2007, un documentaire réalisé par la chaîne locale du département de Fukui, Gokei no kei. Yamasato no chûgokujin wo otte (Liens de réciprocité. Sur les traces de trois stagiaires chinois dans un village de campagne), qui a remporté un prix national du documentaire, décrivait les relations quasi familiales entre trois stagiaires chinois et un couple âgé propriétaire d'une petite entreprise de confection qui témoignait en ces termes: "Sans eux nous aurions fermé."

La présence des stagiaires-apprentis est certes "invisible" dans les grandes villes, mais dans les petites localités dont les entreprises font face à un cruel manque de main-d'œuvre, leur présence est une question de premier plan. 